Bangladesh J. Plant Taxon. 21(2): 193-195, 2014 (December)

(C) 2014 Bangladesh Association of Plant Taxonomists

\title{
NEOTYPIFICATION OF OPHIORRHIZA HUNANICA H. S. LO (RUBIACEAE), A SPECIES ENDEMIC TO HUNAN, CHINA
}

\author{
Lin-Dong Duan, Yun Lin ${ }^{1,2}$ AND QI Lin ${ }^{3}$ \\ Shaoyang University, Shaoyang 422004, Hunan, People's Republic of China \\ Keywords: Neotype; Typification; Ophiorrhiza hunanica; Rubiaceae; China.
}

The genus Ophiorrhiza L. (Rubiaceae) consists of c. 200-300 species distributed in tropical and subtropical Asia, Australia, New Guinea, and the Pacific islands. In China, Ophiorrhiza is represented by 70 species (Chen and Taylor, 2011).

A single specimen with flower buds was designated the type of Ophiorrhiza hunanica H. S. Lo from Hunan. In the protologue of this name, only the stems, leaves and flower buds were described for this species, without descriptions of mature flowers, fruits and seeds (Lo, 1990). This species was included in the Flora Reipublicae Popularis Sinicae (Lo, 1999), and the Flora of China (Chen and Taylor, 2011) with the same description.

As part of our work on the Flora of Hunan, we have been searching for this type specimen at the Herbarium (HUTM) of Institute of Chinese Materia Medica, in Hunan Academy of Traditional Chinese Medicine and Pharmacy, where the type specimen was supposed to be preserved, and the Herbarium (IBSC) of Department of Taxonomy, South China Institute of Botany, Chinese Academy of Sciences where the author H. S. Lo worked for many times. We have found that both the type specimens and any other original material were lost during the relocation of the herbarium HUTM, and were not also deposited at the herbarium IBSC. We have collected this plant as flower bud specimens, flowering specimens and fruiting specimens from the type locality, which is in Chenjia Group, Hengyan Village, Xiaojia Township, Huitong County, Hunan Province of South Central China. Dissection and observation of these specimens confirm the morphological characteristics coincide with original descriptions, and allow preparation of a complete description of this species.

Following Article 9.7 and 9.16 of International Code of Nomenclature for algae, fungi, and plants (Melbourne Code) (McNeill et al., 2012), neotype for this name Ophiorrhiza hunanica H. $\mathrm{S}$. Lo is here designated because the holotype is lost, and detailed morphological description, distribution, habitat, phenology, and photographs of the living plants are provided for this species.

Ophiorrhiza hunanica H. S. Lo in Bull. Bot. Res., Harbin 10(2): 24 (1990).

(Figs 1 \& 2).

Type: China. Hunan Province: Huitong Country, Xiaojia Township, Hengyan Village, Chenjia Group, alt. 300 m, 16 Nov. 1985, Huitong Herb. Medic. Exped. 980 (Holotype: HUTM, lost); the same locality, alt. 380 m, 26 Mar. 2012, L. D. Duan \& Q. Lin 5191 (flower with short style) (Neotype, designated here, PE; isoneotypes, BM, E, HUFD, HUSY, IBSC, K, KUN, L, MO, P).

\footnotetext{
${ }^{1}$ Department of Chinese Materia Medica, Hunan Food and Drug Vocational College, Changsha 410208, Hunan, People's Republic of China

${ }^{2}$ Corresponding author. Email: leoliny@foxmail.com

${ }^{3}$ China National Herbarium (PE), State Key Laboratory of Systematic and Evolutionary Botany, Institute of Botany, Chinese Academy of Sciences, Beijing 100093, People's Republic of China
} 
Herbs, procumbent at base or repent, 13-21 cm tall. Stems fleshy, brown to black after drying, multicellular-villous. Leaves in unequal pairs; petiole 1-6 cm, densely multicellular-villous; blade papery after drying, purple on veins, elliptic, obovate-oblong, obovate, or ovate, (4.0-) 7.5-23.0 × (2.0-) 3.0-7.5 cm, adaxially sparsely hirtellous-strigose, abaxially subglabrous or villous on veins, base cuneate, margin entire, apex obtuse to subacute; secondary veins 7-14 pairs; stipules often persistent, ovate to ovate-lanceolate, 5-15 mm acuminate, ciliate. Inflorescence cymose, terminal, 5- to many-flowered, densely multicellular-villous, pendulous; peduncle $3-8 \mathrm{~cm}$, arching, densely multicellular-villous; principal axes 2-4 pairs, helicoid. Bracts linear, 8-25 × 1-2 mm, sparsely pinnately veined, sparsely ciliate. Flowers distylous, pedicels 1-3 mm long. Calyx with hypanthium compressed-turbinate, c. $2 \mathrm{~mm}$ long, 5-ribbed, densely multicellular-villous; lobes 5, linear, 5-7 mm, hispidulous along costa. Corolla purple, funnelform, outside glabrous or glabrescent, longitudinally winged, inside pubescent, purple near middle and white in lobes; tube 15-18 mm long; lobes 5, ovate, white, 4-6 mm long, apex rostrate. Stamens 5, inserted near throat or below middle of corolla tube, exserted or included; filaments $2.5-3.0 \mathrm{~mm}$ in short-styled or 0.5$0.7 \mathrm{~mm}$ in long-styled; anthers 3.0-3.5 mm, dorsifixed. Ovary 2-celled, ovules numerous in each cell; style 5-6 mm or $15-17 \mathrm{~mm}$ long; stigmas 2, linear or subcapitate, included or exserted. Capsules purple, mitriform, strongly laterally compressed, 5.0-5.5 × 10-12 mm, multicellularvillose. Seeds numerous, small.

Phenology: Flowering from February to March and fruiting from April to May.

Habitat: This species was only observed to grow in streamsides in evergreen broad-leaved forests at altitudes of 300-390 m, comprising 400 individuals growing in more than ten populations within a nature reserve of a square kilometer.
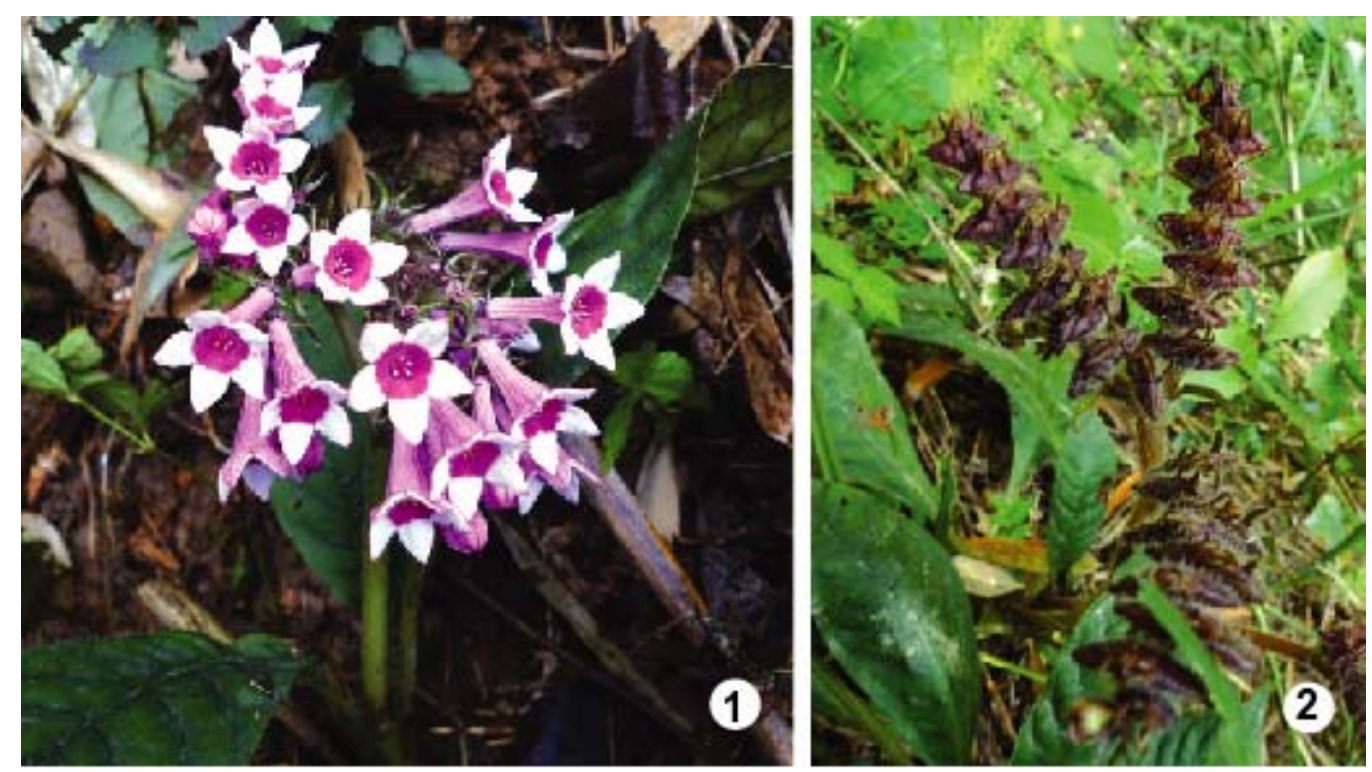

Figs 1-2. 1. Ophiorrhiza hunanica H. S. Lo. (L. D. Duan \& Q. Lin 5191, PE) - Habitat of flowering plant with short style. 2. O. hunanica H. S. Lo. (L. D. Duan \& Y. Lin 5242, PE) - Habitat of fruiting plant.

Distribution: Ophiorrhiza hunanica is only known from its type locality, Hengyan Village, Xiaojia Township, Huitong County, Hunan Province, South Central China. 
Additional specimens examined: China: Hunan Province: Huitong Country, Xiaojia Township, Hengyan Village, Chenjia Group, alt. 320 m, 18 Dec. 2011, L. D. Duan 5183 (flower bud), HUFD (Herbarium, Hunan Food and Drug Vocational College, Hunan, China), HUSY (Herbarium, Shaoyang University, Hunan, China), PE (China National Herbarium, Institute of Botany, Chinese Academy of Sciences, Beijing, China); the same locality, alt. 380 m, 26 Mar. 2012, L. D. Duan \& Q. Lin 5190 (flower with long style) (HUFD, HUSY, PE); the same locality, alt. $380 \mathrm{~m}, 1$ May 2013, L. D. Duan \& Y. Lin 5242 (fr.) (HUFD, HUSY, PE).

\section{Acknowledgement}

This work has been supported by Key Project for the Development of State Facilities and Information Infrastructure for Science and Technology: National Specimen Information Infrastructure (2005DKA21401).

\section{References}

Chen, T. and Taylor, C.M. 2011. Ophiorrhiza (Rubiaceae). In: Wu Z.Y. and Raven P.H. (Eds), Flora of China, Vol. 19. Science Press, Beijing, and Missouri Botanical Garden Press, St. Louis, pp. 258-282.

Lo, H.S. 1990. Taxonomic revision of the Chinese species of Ophiorrhiza (Rubiaceae). Bull. Bot. Res., Harbin 10(2): 1-82.

Lo, H.S. 1999. Ophiorrhiza (Rubiaceae). In: Lo, H.S. (Ed.), Flora Reipublicae Popularis Sinicae, Vol. 71(1). Science Press, Beijing, pp. 110-174.

McNeill, J., Barrie, F.R., Buck, W.R., Demoulin, V., Greuter, W., Hawksworth, D.L., Herendeen, P.S., Knapp, S., Marhold, K., Prado, J., Prud'Homme van Reine W.F., Smith, G.F. and Wiersema, J.H. 2012. International Code of Nomenclature for algae, fungi, and plants (Melbourne Code). Konigstein: Koeltz Scientific Books, pp. 1-152. 